\title{
A highly efficient, eco-friendly, room temperature synthesis of bis(indol-3-yl)methanes using the mesoporous titanosilicate Ti-TUD-1: electrophilic substitution reactions of indoles - Part XXIII
}

\author{
Bikash Karmakar, ${ }^{a}$ Anupam Nayak, ${ }^{a}$ Biswajit Chowdhury ${ }^{b^{*}}$ and Julie Banerji ${ }^{\mathrm{a} *}$ \\ ${ }^{a}$ Centre of Advanced Studies on Natural Products including Organic Synthesis, Department of \\ Chemistry, University of Calcutta, 92, A.P.C. Road, \\ Kolkata-700009, India \\ ${ }^{b}$ Department of Applied Chemistry, Indian School of Mines University, \\ Dhanbad-826004, India \\ E-mail:juliebanerji47@gmail.com; biswajit_chem2003@yahoo.com
}

\begin{abstract}
Bis(indol-3-yl)methanes have been synthesized at room temperature in high yields by the reaction of indole or 2-methylindole with aromatic aldehydes using the titanosilicate catalyst TiTUD-1 for the first time. The catalyst was recycled and reused five times with reproducible yields. This procedure has the advantage of high yields at room temperature, mildness of reaction conditions, operational simplicity and reusable nature of the catalyst which makes this protocol practically useful for the synthesis of bis(indol-3-yl)methanes.
\end{abstract}

Keywords: Titanosilicate, bis(indol-3-yl)methane, room temperature, recyclable.

\section{Introduction}

Ever since the biochemical ${ }^{1}$ and clinical $^{2}$ use of various indole derivatives viz., bis(indol-3yl)methane, ${ }^{3}$ vibrindole $\mathrm{A}^{4}$ and streptindole ${ }^{5}$ was reported, attention has been focused on the development of cost-effective, simple operational procedures and high yield routes to bis(indol3-yl)methanes (BIMs) and substituted bis(indol-3-yl)methanes. ${ }^{6}$ In this communication we report, for the first time, the use of Ti-TUD-1, a mesoporous titanosilicate ${ }^{7}$ catalyst for the synthesis of BIMs from the reaction of indoles with various aldehydes at room temperature. We have exploited the high surface area, larger pores, high Lewis acidic character and reusable 
nature of the catalyst in synthesizing bis(indol-3-yl)methanes with high chemoselectivity and in quantitative yields following a clean and green pathway.

\section{Results and Discussion}

Mesoporous Ti-TUD-1 $(\mathrm{Ti} / \mathrm{Si}$ mole ratio $=0.01,0.03,0.05$, named as catalyst $\mathrm{x}, \mathrm{y}, \mathrm{z}$ respectively) catalyst was prepared by non-hydrothermal sol-gel technique and was modified from that followed by T. Maschmeyer et al. ${ }^{7}$ It was then characterized by Transmission Electron Microscopy (TEM) and surface area analysis by Brunauer, Emmett and Teller (BET) method. TEM images (Figure 1) of the catalyst clearly show that the surface is highly porous in nature and is of a spongy type. There are mixtures of small and large pores well distributed over the whole surface. The pore sizes range between $5-15 \mathrm{~nm}$. The porous channels formed are also visible in the TEM image. Due to the high porosity its surface area is also found to be high. BET measurement showed that the surface areas range between $380-450 \mathrm{~m}^{2} / \mathrm{g}$ for the three catalysts. The mesoporosity was also confirmed from X-ray powder diffraction (XRD) studies. The high surface area ensured greater accessibility of the substrates to the active sites of the catalyst.

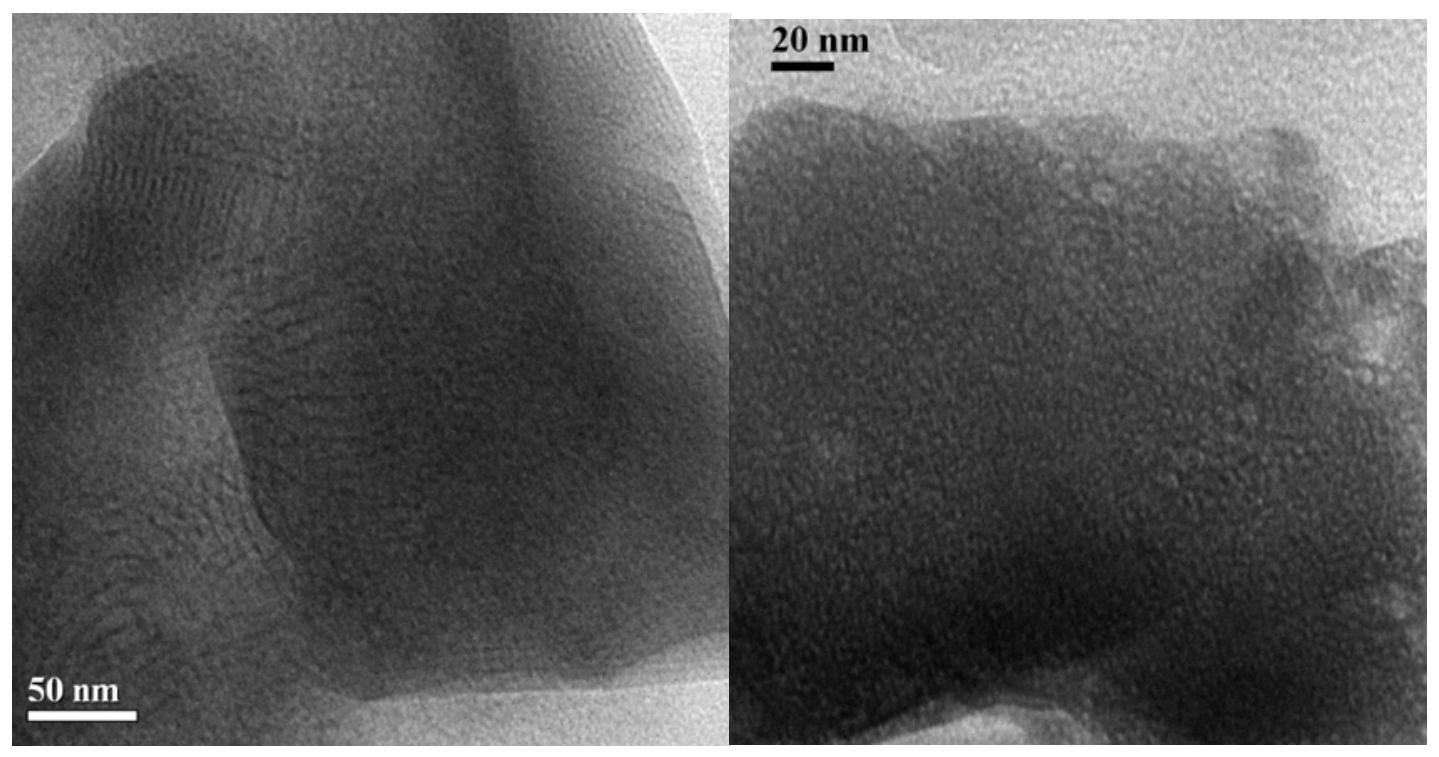

(A)

Figure 1. TEM images of the lamellar channels (A) and porous surface (B) of the catalyst

Due to its Lewis acid character, enhanced by the electron pull of the $\mathrm{Si}$ atom in the Ti-O-Si bond, and large surface area, Ti-TUD-1 could be effectively used as catalyst for the electrophilic substitution reaction of indoles with aromatic aldehydes for the formation of BIMs (Scheme 1). In order to confirm the efficiency of this catalyst, a comparative study was carried out with a 
variety of catalysts along with the Ti-TUD-1 with different $\mathrm{Ti}$ loadings and the results are summarized in Table 1. Indole was treated with benzaldehyde as a model reaction in the presence of the catalyst in dry DCM and under $\mathrm{N}_{2}$ flow. The reaction did not proceed in the absence of any catalyst. Also, with unloaded mesoporous silicate TUD-1 and bulk $\mathrm{TiO}_{2}$ as catalysts, no product was obtained. Other titanosilicates like Ti-MCM-48 and TS-1 did not prove to be highly efficient in this reaction. Ti-TUD-1 catalysts with different $\mathrm{Ti} / \mathrm{Si}$ content were studied and it was observed that with a $\mathrm{Ti} / \mathrm{Si}$ mol ratio 0.03 (catalyst $\mathrm{y}$ ) provided the best result. The optimization of the conditions was continued using the best catalyst with different solvent variations. We tried several solvents of variable polarity and the observations are shown in Table 2. The reaction proceeded smoothly with the best yield $(89 \%)$ in dry dichloromethane. Other solvents like toluene, chloroform, acetonitrile and tetrahydrofuran resulted in low to moderate yields. In the absence of solvent, no product was obtained.

Table 1. Study of catalyst variation in the synthesis of bis(indol-3-yl)methanes ${ }^{\mathrm{a}}$

\begin{tabular}{cccc}
\hline Entry & Catalyst & Time (h) & Yield $^{\mathrm{b}}(\%)$ \\
\hline 1 & None & 24 & - \\
2 & TUD-1 & 24 & - \\
3 & TiO $_{2}$ & 24 & - \\
4 & Ti-MCM-48 & 24 & 57 \\
5 & Ti-TUD-1 (x) & 6 & 85 \\
$\mathbf{6}$ & Ti-TUD-1 (y) & $\mathbf{6}$ & $\mathbf{8 9}$ \\
7 & Ti-TUD-1 (z) & 6 & 78 \\
8 & TS-1 & 12 & 48 \\
\hline
\end{tabular}

${ }^{\mathrm{a}}$ reaction conditions: $2 \mathrm{mmol}$ benzaldehyde, $4 \mathrm{mmol}$ indole, $10 \mathrm{mg}$ catalyst, room temperature. ${ }^{\mathrm{b}}$ isolated yield after purification

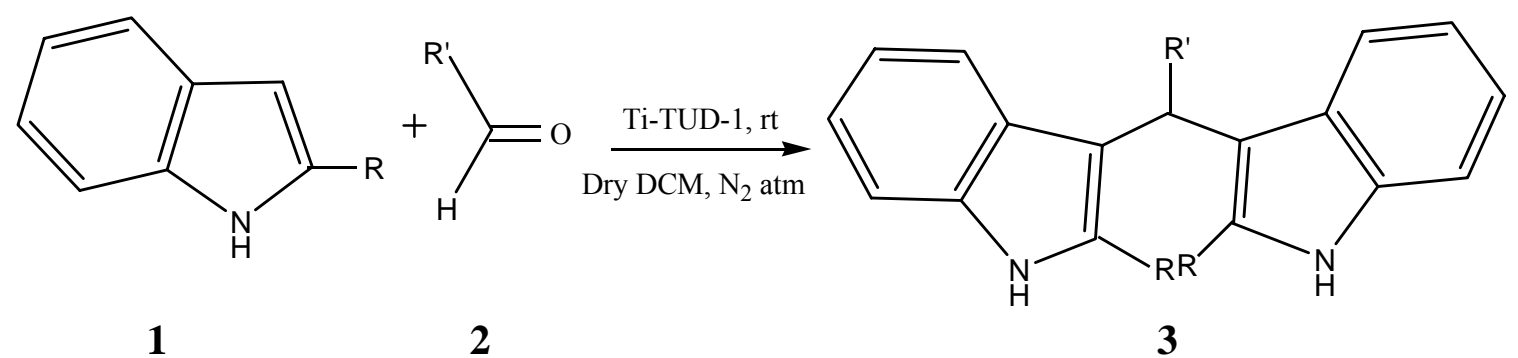

Scheme 1. Mesoporous titanosilicate catalyzed synthesis of bis(indol-3-yl)methanes 3. 
Table 2. Use of Ti-TUD-1 catalyst in various solvents ${ }^{\mathrm{a}}$

\begin{tabular}{clcc}
\hline Entry & Solvent & Time $(\mathrm{h})$ & Yield $^{\mathrm{b}}(\%)$ \\
\hline 1 & None & 24 & - \\
$\mathbf{2}$ & Dichloromethane & $\mathbf{6}$ & $\mathbf{8 9}$ \\
3 & Chloroform & 12 & 35 \\
4 & Toluene & 24 & 15 \\
5 & Acetonitrile & 12 & 52 \\
6 & Tetrahydrofuran & 12 & 32 \\
\hline
\end{tabular}

${ }^{a}$ reaction conditions: $2 \mathrm{mmol}$ benzaldehyde, $4 \mathrm{mmol}$ indole, $10 \mathrm{mg}$ catalyst, room temperature. ${ }^{\mathrm{b}}$ isolated yield after purification.

A series of reactions were carried to study the scope and generality of Ti-TUD-1 (y) catalyst using various aromatic aldehydes and two indoles. The results are shown in Table 3. The bis(indol-3-yl)methanes 3a-o were synthesized utilizing indole 1a and 2-methylindole $\mathbf{1 b}$ with a variety of aromatic aldehydes 2a-I under the optimum conditions. In all the cases, BIMs were obtained as the sole products. Most of the aldehydes reacted with indoles to produce the bis(indol-3-yl)methanes in high yields. The effect on the yields of electron-withdrawing or electron-donating substituents on the aldehydes is shown in Table 3 (entries 2 and 7). It was observed that the reaction proceeded faster and in better yields with 2-methylindole $\mathbf{1 b}$ than with indole 1a possibly due to higher electron density at C-3. With indole, the reaction time was between 6-8 hours, while with 2-methylindole the reaction was complete within 45-120 minutes depending upon the electrophiles used. However, the catalyst did not show any activity towards ketones, viz., acetone $\mathbf{2 m}$, acetophenone $\mathbf{2 n}$ and cyclohexanone $\mathbf{2 0}$. After prolonged reaction time at room temperature as well as on heating up to $60{ }^{\circ} \mathrm{C}$ both starting materials remained unchanged. This can be attributed to the lower electrophilicity of ketones compared to aldehydes. 
Table 3. Synthesis of bis(indol-3-yl)methanes over mesoporous titanosilicate Ti-TUD-1 ${ }^{\mathrm{a}}$

\begin{tabular}{|c|c|c|c|c|}
\hline Entry & $\mathbf{R}$ & $\mathbf{R}^{\prime}$ & Product 3 & Yield $^{\mathrm{b}}(\%)$ \\
\hline 1 & H (1a) & $\mathrm{C}_{6} \mathrm{H}_{5}$ (2a) & $3 a$ & 89 \\
\hline 2 & H (1a) & $\left(4-\mathrm{NO}_{2}\right) \mathrm{C}_{6} \mathrm{H}_{4}(\mathbf{2 b})$ & $3 \mathbf{b}$ & 94 \\
\hline 3 & H (1a) & $(4-\mathrm{Me}) \mathrm{C}_{6} \mathrm{H}_{4}(2 \mathrm{c})$ & $3 c$ & 78 \\
\hline 4 & H (1a) & (4-Cl) $\mathrm{C}_{6} \mathrm{H}_{4}$ (2d) & 3d & 84 \\
\hline 5 & H (1a) & $\left(3-\mathrm{NO}_{2}\right) \mathrm{C}_{6} \mathrm{H}_{4}(\mathbf{2 e})$ & $3 \mathbf{e}$ & 91 \\
\hline 6 & H (1a) & $(4-\mathrm{OH}) \mathrm{C}_{6} \mathrm{H}_{4}$ (2f) & $3 f$ & 71 \\
\hline 7 & H (1a) & $\left(4-\mathrm{NMe}_{2}\right) \mathrm{C}_{6} \mathrm{H}_{4}(2 \mathrm{~g})$ & $3 g$ & 64 \\
\hline 8 & H (1a) & $(4-\mathrm{OMe}) \mathrm{C}_{6} \mathrm{H}_{4}$ (2h) & $3 h$ & 73 \\
\hline 9 & $\mathrm{H}$ (1a) & $(4-\mathrm{OH})(3-\mathrm{OMe}) \mathrm{C}_{6} \mathrm{H}_{3}(2 \mathrm{i})$ & $3 \mathbf{i}$ & 62 \\
\hline 10 & H (1a) & $(3,4-\mathrm{di} \mathrm{OMe}) \mathrm{C}_{6} \mathrm{H}_{3}(2 \mathbf{j})$ & $3 \mathbf{j}$ & 75 \\
\hline 11 & H (1a) & $(3,4,5$-tri OMe $) \mathrm{C}_{6} \mathrm{H}_{2}(\mathbf{2 k})$ & $3 \mathbf{k}$ & 78 \\
\hline 12 & Me (1b) & $\mathrm{C}_{6} \mathrm{H}_{5}(2 \mathrm{a})$ & 31 & 91 \\
\hline 13 & $\operatorname{Me~(1b)~}$ & $\left(4-\mathrm{NO}_{2}\right) \mathrm{C}_{6} \mathrm{H}_{4}(\mathbf{2 b})$ & $3 m$ & 96 \\
\hline 14 & $\operatorname{Me~(1b)~}$ & (4-Cl) $\mathrm{C}_{6} \mathrm{H}_{4}$ (2d) & $3 n$ & 86 \\
\hline 15 & $\operatorname{Me~(1b)~}$ & furoyl (2l) & 30 & 88 \\
\hline 16 & H (1a) & acetone (2m) & - & - \\
\hline 17 & H (1a) & cyclohexanone (2n) & - & - \\
\hline 18 & H (1a) & acetophenone (2o) & - & - \\
\hline
\end{tabular}

a reaction conditions: $2 \mathrm{mmol}$ carbonyl compound, $4 \mathrm{mmol}$ indole, $10 \mathrm{mg}$ catalyst, room temperature.

$\mathrm{b}$ isolated yield after purification.

Ti-TUD-1 is a very stable catalyst and can be recycled. It was reused for five consecutive times after being dried at $100{ }^{\circ} \mathrm{C}$ for 2 hours. No appreciable loss in its catalytic activity was observed as is evident from the yields (Figure 2). The high catalytic activity of Ti-TUD-1 is probably due to the high accessibility of the substrate molecules to the catalytic sites of the mesoporous system where $\mathrm{Ti}^{4+}$ is in tetrahedral coordination and being symmetrically dispersed over the three dimensional surface. Regarding the mechanism, it can be presumed that Ti-O-Si linkages at the surface bind with the aldehyde oxygen and increase the carbonyl activity. Indole then attacks the activated carbonyl to generate an indolenium cation. This intermediate, being unstable, is attacked by a second indole molecule and subsequent loss of water resulting in the formation of bis(indol-3-yl)methane. 


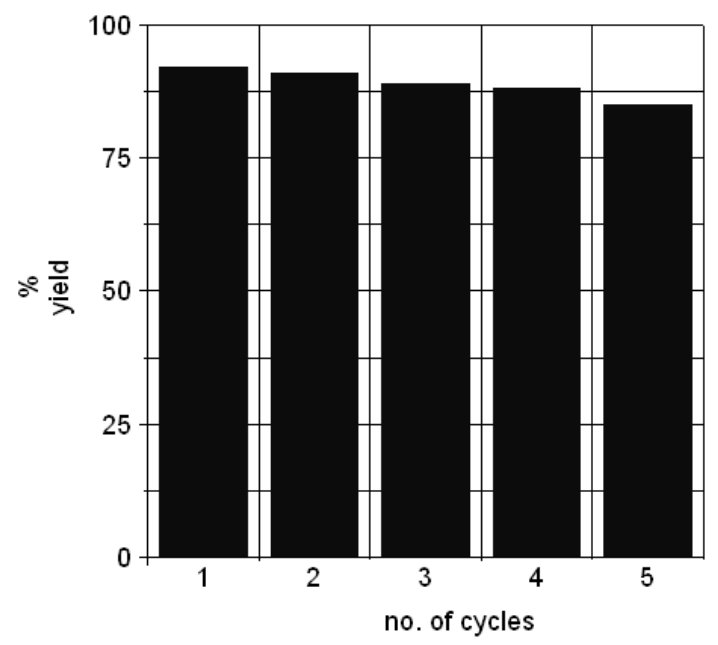

Figure 2. Recycling of the catalyst $\mathrm{t}^{\mathrm{a}}$

a reaction conditions: $2 \mathrm{mmol}$ benzaldehyde, $4 \mathrm{mmol}$ indole, $10 \mathrm{mg}$ catalyst, room temperature, isolated yield.

\section{Experimental Section}

All chemicals were of analytical grade and used as such without further purification. The solvents were purified by distillation. All IR spectra were recorded on Perkin Elmer RX-1 FTIR spectrophotometer. ${ }^{1} \mathrm{H}$ NMR and ${ }^{13} \mathrm{C}$ NMR were done on Bruker-Avance Digital $300 \mathrm{MHz}$ and 75.5 MHz Spectrometer. ${ }^{1} \mathrm{H}$ NMR and ${ }^{13} \mathrm{C}$ NMR were done on Bruker-Avance Digital $300 \mathrm{MHz}$ and $75.5 \mathrm{MHz}$ Spectrometer. TMS was used as internal standard. A JEOL JMS 600 mass spectrometer was used to record the HRMS. TEM images were obtained from a Hitachi H-9000 NAR Transmission Electron Microscope at an operating voltage of $100 \mathrm{kV}$. The sample was prepared by placing one drop dispersed solution of the catalyst in acetone solvent on a carbon coated copper grid followed by drying in air. Melting points (uncorrected) were determined on a Köfler Block apparatus. Analytical TLC was performed using E. Merck aluminium-backed silica gel plates coated with silica gel G and monitored under UV light (254 and $360 \mathrm{~nm}$ ) and also by exposing to iodine. Indole, aldehydes and ketones were purchased from Merck.

\section{Typical procedure for the preparation of modified Ti-TUD-1 catalyst}

A modified sol-gel method was used to prepare mesoporous titanosilicate catalyst. Tetraethyl orthosilicate (TEOS) (Acros 99.5\%) and titanium (IV) butoxide (Acros 99\%) were used as the precursor for silica and titanium respectively. In the typical procedure, titanium butoxide was added slowly to the TEOS solution. A mixture of triethanolamine (TEA) (Acros 99\%) and deionised water was added to a stirring solution and then triethyl ammonium hydroxide 
(TEAOH) (E-Merck) (20\% aqueous solution) was added dropwise to maintain $\mathrm{pH}$ 9. The final molar ratio of the reagents was $1.0 \mathrm{SiO}_{2}: 0.03 \mathrm{TiO}_{2}: 3.0$ TEA: $0.3 \mathrm{TEAOH}: 15 \mathrm{H}_{2} \mathrm{O}$. The solution was aged for 24 hours at room temperature. It was then dried at $115^{\circ} \mathrm{C}$ for 16 hours and finally calcined at $700{ }^{\circ} \mathrm{C}$ for 12 hours at the rate of $2{ }^{\circ} \mathrm{C} /$ minute under the flow of air.

\section{Typical procedure for the synthesis of bis(indol-3-yl)methanes}

A mixture of benzaldehyde (98 $\mathrm{mg}, 2 \mathrm{mmol})$ and indole $(200 \mathrm{mg}, 4 \mathrm{mmol})$ were taken in a $50 \mathrm{~mL}$ round-bottom flask containing $5 \mathrm{~mL}$ dry dichloromethane. Ti-TUD-1 catalyst $(10 \mathrm{mg})$ was then added and the reaction mixture stirred continuously at room temperature under nitrogen atmosphere till the full consumption of starting materials was observed (TLC). After the completion of reaction the catalyst was filtered carefully. The residue obtained was washed with ethyl acetate, dried at $100{ }^{\circ} \mathrm{C}$ and reused as catalyst. The filtrate was evaporated under reduced pressure to give the crude product which was purified by column chromatography using neutral alumina and appropriate ethyl acetate/petroleum ether mixtures as eluent. All the isolated products were known. They were characterized by melting point measurement, IR spectroscopy, ${ }^{1} \mathrm{H}$ NMR, ${ }^{13} \mathrm{C}$ NMR and HRMS spectrometry and elemental analysis $(\mathrm{C}, \mathrm{H}, \mathrm{N})$ and were compared to their authentic data. ${ }^{8}$

\section{Acknowledgements}

J.B. and A.N. thank UGC (New Delhi) for providing the funds. BC also thanks Fast Track Young Scientist Scheme under DST (New Delhi) for financial assistance. BK thanks Mr. P. Ghosh for Instrumnetal analysis at Calcutta University and IIT, Kharagpur for TEM analysis.

\section{References}

1. (a) Lo, K. K.-W.; Tsang, K. H.-K.; Hui, W.-K.; Zhu, N. Chem. Commun. 2003, 2704. (b) Ramirez, A.; Garcia-Rubio, S. Curr. Med. Chem. 2003, 10, 1891.

2. (a) Le, H. T.; Schaldach, C. M.; Firestone, G. L.; Bjeldanes, L. F. J. Biol. Chem. 2003, 278, 21136. (b) Dalessandri, K. M.; Firestone, G. L.; Fitch, M. D.; Bradlow, H. L.; Bjeldanes, L. F. Nutr. Cancer. 2004, 50, 161.

3. (a) Maciejewska, D.; Rasztawicka, M.; Wolska, I.; Anuszewska, E.; Gruber, B. Eur. J. Med. Chem. 2009, 44, 4136. (b) Karthik, M.; Tripathi, A. K.; Gupta, N. M.; Palanichamy, M.; Murugeson, V. Catal. Commun. 2004, 5, 371. (c) Gribble, G. W. J. Chem. Soc., Perkin Trans 1, 2000, 1045.

4. Deb, M. L.; Bhuyan, P. J. Synthesis 2008, 2891. 
5. (a) Bartoli, G.; Bosco, M.; Foglia, G.; Giuliani, A.; Marcantoni, E.; Sambri, L. Synthesis 2004, 895. (b) Chakrabarty, M.; Ghosh, N.; Basak, R.; Harigaya, Y. Synth. Commun. 2004, $34,421$.

6. (a) Pindur, U.; Adam, R. J. Heterocycl. Chem. 1988, 25, 1. (b) Rainer, J. D.; Smith, A. B. Tetrahedron Lett. 2000, 41, 9419. (c) Bennasar, M.-L.; Vidal, B.; Bosch, J. J. Org. Chem. 1997, 62, 3597. (d) Amat, M.; Hadida, S.; Pshenichnyi, G.; Bosch, J. J. Org. Chem. 1997, 62, 3158. (e) Azizian, J.; Teimouri, M. R.; Mohammadizadeh, M. R. Catal. Commun. 2007, 8, 1117. (f) Ramesh, R.; Banerjee, J.; Pal, R.; Das, B. Adv. Synth. Catal. 2003, 345, 557. (g) Chakrabarty, M.; Basak, R.; Harigaya, Y.; Ghosh, N. Tetrahedron Lett. 2002, 43, 4075. (h) Maiti, A. K.; Bhattacharyya, P. J. Chem Res. (S) 1997, 425. (i) Li, J.; Zhou, M.; Li, B.; Zhang, G. Synth. Commun. 2004, 34, 275. (j) Ji, S. -J.; Zhou, M. -F.; Gu, D. -G.; Wang, S. Y.; Loh, T. -P. Synlett 2003, 13, 2077. (k) Ji, S. -J.; Zhou, M. -F.; Gu, D. -G.; Ziang, Z. -Q.; Loh, T. -P. Eur J. Org. Chem. 2004, 1584. (1) Yadav, J. S.; Reddy, B. V. S.; Sunitha, S. Adv. Synth. Catal. 2003, 345, 349. (m) Bandgar, B. P.; Shaikh, K. A. Tetrahedron Lett. 2003, 44, 1959. (n) Yadav, J. S.; Reddy, B. V. S.; Murthy, Ch. V. S. R.; Kumar, G. M.; Madan, Ch. Synthesis 2001, 783. (o) Firouzabadi, H.; Iranpoor, N.; Javari, A. A. J. Mol. Catal. A : Chemical 2006, 244, 168. (p) Chatterjee, A.; Manna, S.; Banerji, J.; Pascard, C.; Prange, T.; Shoolery, J.; James, N. J. Chem. Soc., Perkin Trans. 1 1980, 553. (q) Chen, D.; Yu, L.; Wang, P. G. Tetrahedron Lett. 1996, 37, 4467. (r) Wang, L.; Han, J.; Tian, H.; Sheng, J.; Fan, Z.; Tang, X. Synlett 2005, 2, 337. (s) Ramesh, C.; Ravindranath, N.; Das, B. J. Chem Res. (S) 2003, 72. (t) Zolfigol, M.; Salehi, P.; Shiri, M. Phosphorous, Sulfur, Silicon Rel. Elem. 2004, 179, 2273. (u) Bavanthula, R; Reddy, P. N; Kumar, B. S; Neeladri, S; Reddy, Y; Reddy, T. J. Chem Res. 2005, 222. (v) Seyedi, N.; Saidi, K.; Khabazzadeh, H. Synth. Commun. 2009, 39, 1864. (w) Praveen, C; Wilson Sagayaraj, Y.; Perumal, P. T.; Tetrahedron Lett. 2009, 50, 644. (x) Sabitha, G.; Reddy, N. M.; Prasad, M. N.; Yadav, J. S.; Sivudu, K. S.; Shailaja, D. Lett. Org. Chem. 2008, 5, 300. (y) Nadkarni, S. V.; Gawande, M. B.; Jayaram, R. V.; Nagarkar, J. M. Catal. Commun. 2008, 9, 1728. (z) Khalafi-Nehzad, A.; Parhami, A.; Zare, A.; Zare, A. R. Moosavi; Hasaninejad, A.; Panahi, F. Synthesis, 2008, 617.

7. Shan, Z; Gianotti, E; Jansen, J. C; Peters, J. A; Marchese, L; Maschmeyer, T. Chem. Eur. J. 2001, 7, 1437.

8. (a) Selvam, J. J. P.; Srinivasulu, M.; Suryakiran, N.; Suresh, V.; Malla Reddy, S.; Venkatesarlu, Y. Synth. Commun. 2008, 38, 1760. (b) Sobhani, S.; Safaei, E.; Hasaninejad, A.-R.; Rezazadeh, S. J. Organomet. Chem. 2009, 694, 3027. (c) Sadaphal, S. A.; Shelke, K. F.; Sonar, S. S.; Shingare, M. S. Eur. J. Chem. 2008, 6, 622. (d) Zahran, M.; Abdin, Y.; Salama, H. Arkivoc 2008, 256. (e) Teimouri, M. B.; Mivehchi, H. Synth. Commun. 2005, 35, 1835. 